\title{
Challenges with Disaster Mortality Data and Measuring Progress Towards the Implementation of the Sendai Framework
}

\author{
Helen K. Green ${ }^{1}$ - Oliver Lysaght ${ }^{1}$ - Dell D. Saulnier ${ }^{2} \cdot$ Kevin Blanchard $^{1}$ • \\ Alistair Humphrey ${ }^{3} \cdot$ Bapon Fakhruddin $^{4} \cdot$ Virginia Murray $^{1}$
}

Published online: 30 October 2019

(C) The Author(s) 2019

\begin{abstract}
Disasters exact a heavy toll globally. However, the degree to which we can accurately quantify their impact, in particular mortality, remains challenging. It is critical to ensure that disaster data reliably reflects the scale, type, and distribution of disaster impacts given the role of data in: (1) risk assessments; (2) developing disaster risk management programs; (3) determining the resources for response to emergencies; (4) the types of action undertaken in planning for prevention and preparedness; and (5) identifying research gaps. The Sendai Framework for Disaster Risk Reduction 2015-2030s seven global disaster-impact reduction targets represent the first international attempt to systematically measure the effectiveness of disaster-impact reduction as a means of better informing policy with evidence. Target A of the Sendai Framework aims to "substantially reduce global disaster mortality by 2030, aiming to lower the average per 100,000 global mortality rate in the decade 2020-2030 compared to the period 2005-2015." This article provides an overview of the complexities associated with defining, reporting, and interpreting disaster mortality data used for gauging success in meeting Target A, acknowledging different challenges for different types of hazard events and subsequent
\end{abstract}

Virginia Murray

Virginia.Murray@phe.gov.uk

1 Global Disaster Risk Reduction, Public Health England, London SE1 8UG, UK

2 Department of Public Health Sciences, Karolinska Institutet, 17177 Stockholm, Sweden

3 Canterbury District Health Board, Christchurch 8140, New Zealand

4 Disaster Risk Reduction and Climate Resilience, Tonkin + Taylor, Auckland 1141, New Zealand disasters. It concludes with suggestions of how to address these challenges to inform the public health utility of monitoring through the Sendai Framework.

Keywords Data - Disaster mortality - Disaster risk management $\cdot$ Disaster risk reduction $\cdot$ Mass casualty $\cdot$ Sendai Framework

\section{Introduction}

Disasters can result in significant mortality that can be complex to monitor. This section provides the background to this and the purpose of the Sendai Framework, outlining the key aims of this article.

\subsection{Impact of Disasters}

Disasters result from vulnerabilities to a range of hazards, including natural, technological, and biological, among others. They exact a heavy toll globally (European Commission 2018), affecting the well-being and safety of persons, communities, and countries as a whole. Disasters are associated with significant economic, social, health, cultural, and environmental impacts in the short, medium, and long term, especially at the local and community level.

Disasters can impact considerably on people's health and day to day functioning but quantification of the impact, in particular mortality, is very challenging. It is estimated that between 2005 and 2015, more than 1.5 billion people overall had been affected because of disasters, including over 700,000 people losing their lives, more than 1.4 million people being injured, and approximately 23 million people made homeless (UNISDR 2015a). People with higher levels of vulnerability and lower capacity to manage 
disaster risks are disproportionately affected. Factors affecting vulnerability include poverty, gender, age, poor health, and poor nutritional status. While global disaster mortality appears to be declining for some hazards (Bouwer and Jonkman 2018), evidence suggests there is a steady rise in disaster related economic losses and number of people affected, with exposure of persons and assets in all countries increasing faster than vulnerability has decreased, thereby increasing risks (UNISDR 2015a). Disaster risk reduction is therefore a crucial focus for the global community.

\subsection{The Sendai Framework}

Since the 1980s, the United Nations (UN) has engaged in developing frameworks to address the impact of disasters (Fig. 1). After lengthy negotiations, the most recent framework adopted by the UN General Assembly is the Sendai Framework for Disaster Risk Reduction 20152030. It aims to achieve "the substantial reduction of disaster risk and losses in lives, livelihoods and health and in the economic, physical, social, cultural and environmental assets of persons, businesses, communities and countries" over the next 15 years (UNISDR 2015a, p. 12). The Sendai Framework serves to reduce existing risk susceptibility while increasing resilience by multi-hazard assessment, and aims to develop a dynamic, local, preventive, and adaptable system at the global, national, and local levels. It is actively linked to the other major UN Landmark agreements of the Sustainable Development Goals (SDGs-the 2030 agenda), specifically but not limited to Target 1.5, and COP21's Paris Climate Conference (de Souza Boeno 2017), which has provided a rare but significant opportunity to build coherence across these different but overlapping policy areas (Murray et al. 2017b). It has been identified by the UK Office of National Statistics that the issues in reporting on the SDGs and the Sendai Framework indicators provide an opportunity to maximize resources in addressing mortality data gaps and this will ultimately facilitate monitoring global population health (Office for National Statistics 2018a).

\subsection{Global Targets}

To assess global progress against achieving the outcomes and goals of the Sendai Framework, seven targets were agreed to be measured at a global level (Box 1).

\subsection{Disaster Mortality}

Embedded within Sendai Framework's global targets are 38 indicators recommended by the Open-Ended

\section{Box 1: Sendai Framework targets}

Target A Substantially reduce global disaster mortality by 2030 , aiming to lower the average per 100,000 global mortality rate in the decade 2020-2030 compared to the period 2005-2015;

Target $B$ Substantially reduce the number of affected people globally by 2030 , aiming to lower the average global figure per 100,000 in the decade 2020-2030 compared to the period 2005-2015;

Target $C$ Reduce direct disaster economic loss in relation to global gross domestic product (GDP) by 2030;

Target $D$ Substantially reduce disaster damage to critical infrastructure and disruption of basic services, among them health and educational facilities, including through developing their resilience by 2030 ;

Target $E$ Substantially increase the number of countries with national and local disaster risk reduction strategies by 2020;

Target $F$ Substantially enhance international cooperation to developing countries through adequate and sustainable support to complement their national actions for implementation of the present Framework by 2030;

Target $G$ Substantially increase the availability of and access to multi-hazard early warning systems and disaster risk information and assessments to people by 2030 .
Fig. 1 Summary of UN engagement in disasters and the UN adopted frameworks from the 1960 s to 2015 . Source Adapted from UNISDR (2015b)

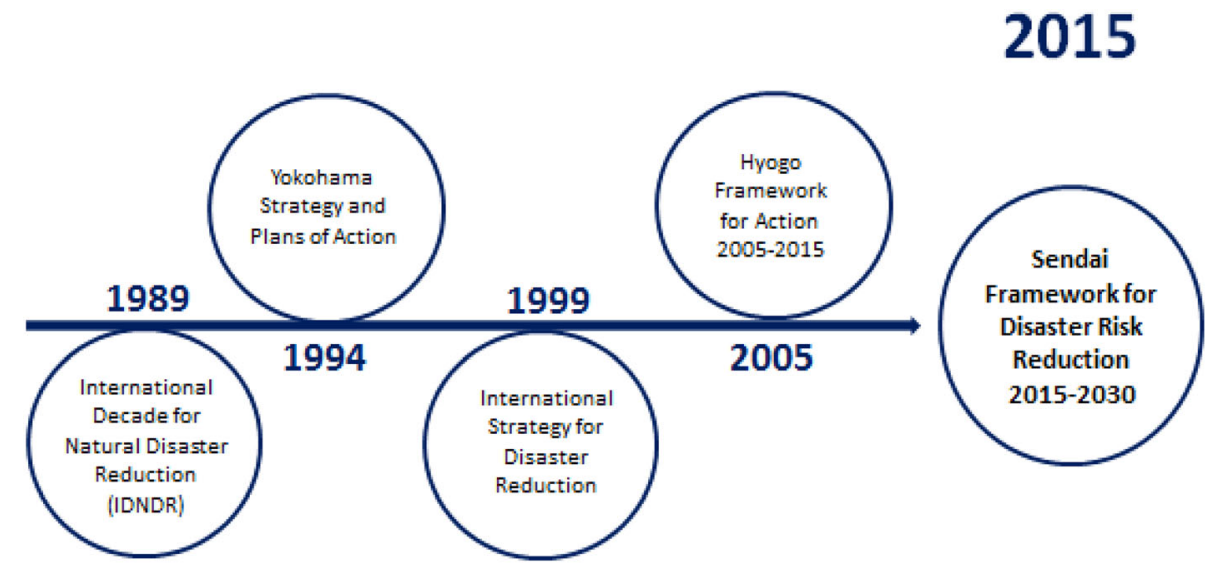


Intergovernmental Expert Working Group (OIEWG) to drive the use of data in informing progress. The UN has recognized the need to improve the data used for monitoring UN Agreement effectiveness in order to better inform policy with evidence (Aitsi-Selmi et al. 2016).

The indicators recommended for annually measuring global Target A on disaster mortality of the Sendai Framework, and which were endorsed by the UN General Assembly in its Resolution A/RES/71/276, "Report of the Open-Ended Intergovernmental Expert Working Group on Indicators and Terminology Relating to Disaster Risk Reduction" are:

A-1 Number of deaths and missing persons attributed to disasters, per 100,000 population;

A-2 Number of deaths attributed to disasters, per 100,000 population;

A-3 Number of missing persons attributed to disasters, per 100,000 population

Disaster mortality is a key outcome that can be used to measure the effectiveness of disaster risk management strategies at reducing the impact of disasters. However, while disaster mortality seems to be one of the simplest outcomes to monitor, obtaining accurate data is challenging-as concluded in a recent panel session on Sendai Framework monitoring at the 2018 Digital Health conference (International Digital Health Conference 2018). A recent estimate of disaster mortality from 1996 to 2015 using data in the International Disaster Database (EMDAT) (CRED 2017) placed this figure at 1.35 million, which is likely to be a significant underestimate. Issues exist around defining disaster mortality, obtaining accurate data, and estimating, interpreting, and reporting mortality data. Information is often incomplete, and estimates are commonly derived from media reports in the early stages of a disaster without being subsequently updated or validated. Another approach is DesInventar (DesInventar 2018), a conceptual and methodological tool for the construction of databases of loss, damage, or effects caused by emergencies or disasters. This was initially developed in Latin America to systematically capture the occurrence and impact of daily disasters of small and medium impact on which information was not previously available. Beyond issues of data completeness, the range of data and variety of ways it is collected and compiled in the databases make comparing data across countries and databases a challenge (OECD 2018).

\subsection{Aim}

To address some of these challenges, guidance on how to measure disaster mortality has been issued as part of the Sendai Framework (UNISDR 2017a). Awareness needs to be raised around the remaining key issues about defining, reporting, and interpreting mortality data to ensure global progress in achieving the outcomes and goals of the Sendai Framework. The aim of this article is therefore to collate in one place an overview of some of the complexities involved with monitoring disaster mortality, including definitions, sources of data, processes for estimating mortality, and suggestions of how to address these challenges to inform the public health utility of monitoring through the Sendai Framework.

\section{Methodological Challenges for Reporting Mortality Data}

The Sendai Framework was endorsed by the UN General Assembly in its Resolution A/RES/71/276 and a review of the readiness of countries participating in the monitoring of progress against the global targets of the Sendai Framework was undertaken in 2017, entitled "Report of the Open-Ended Intergovernmental Expert Working Group on Indicators and Terminology Relating to Disaster Risk Reduction." The review identified that the data required to monitor progress are based on the availability, accessibility, quality, and applicability of multiple datasets, noting that these data are collected from multiple sources via numerous mechanisms, including but not restricted to national disaster-loss accounting systems, national statistical systems, household surveys, and routine administrative data.

Of the 193 UN member states, inputs from 87 were received; 72 had data available on Target $A$, the number of deaths attributed to disasters per 100,000 population. Feedback indicated the considerable work that will need to be undertaken for countries to be able to monitor the agreed indicators in the manner anticipated by the two intergovernmental working groups-the OIEWG and the InterAgency and Expert Group on SDG Indicators. Key points of note for countries were that:

(1) Feasibility and quality of data will be dependent upon the availability and accessibility of the required data;

(2) Data will need to be sufficiently consistent and comparable to allow meaningful measurement of progress and impact.

\section{Defining Disaster Mortality}

How disaster deaths are defined depends on the definition of a hazard [Box 2 (taken from UNISDR 2017b)] and a disaster [Box 3 (taken from UNISDR 2017b)]. When considering the overall definition of a death resulting from 
Box 2: United Nations General Assembly endorsed Report of the Open-nded Intergovernmental Expert Working Group on Indicators and Terminology elated to Disaster Risk Reduction (A/71/644) agreed definition of a Hazard

"A process, phenomenon or human activity that may cause loss of life, injury or other health impacts, property damage, social and economic disruption or environmental degradation."

\section{Annotations}

Hazards may be natural, anthropogenic or socionatural in origin. Natural hazards are predominantly associated with natural processes and phenomena. Anthropogenic hazards, or human-induced hazards, are induced entirely or predominantly by human activities and choices. This term does not include the occurrence or risk of armed conflicts and other situations of social instability or tension which are subject to international humanitarian law and national legislation. Several hazards are socionatural, in that they are associated with a combination of natural and anthropogenic factors, including environmental degradation and climate change.

Hazards may be single, sequential or combined in their origin and effects. Each hazard is characterized by its location, intensity or magnitude, frequency and probability. Biological hazards are also defined by their infectiousness or toxicity, or other characteristics of the pathogen such as dose-response, incubation period, case fatality rate and estimation of the pathogen for transmission.

Multi-hazard means (1) the selection of multiple major hazards that the country faces, and (2) the specific contexts where hazardous events may occur simultaneously, cascadingly or cumulatively over time, and taking into account the potential interrelated effects.

Hazards include (as mentioned in the Sendai Framework for Disaster Risk Reduction 20152030, and listed in alphabetical order) biological, environmental, geological, hydrometeorological and technological processes and phenomena.

Biological hazards are of organic origin or conveyed by biological vectors, including pathogenic microorganisms, toxins and bioactive substances. Examples are bacteria, viruses or parasites, as well as venomous wildlife and insects, poisonous plants and mosquitoes carrying disease-causing agents.

Environmental hazards may include chemical, natural and biological hazards. They can be created by environmental degradation or physical or chemical pollution in the air, water and soil. However, many of the processes and phenomena that fall into this category may be termed drivers of hazard and risk rather than hazards in themselves, such as soil degradation, deforestation, loss of biodiversity, salinization and sea-level rise.

Geological or geophysical hazards originate from internal earth processes. Examples are earthquakes, volcanic activity and emissions, and related geophysical processes such as mass movements, landslides, rockslides, surface collapses and debris or mud flows. Hydrometeorological factors are important contributors to some of these processes. Tsunamis are difficult to categorize: although they are triggered by undersea earthquakes and other geological events, they essentially become an oceanic process that is manifested as a coastal water-related hazard.

Hydrometeorological hazards are of atmospheric, hydrological or oceanographic origin. Examples are tropical cyclones (also known as typhoons and hurricanes); floods, including flash floods; drought; heatwaves and cold spells; and coastal storm surges.

Hydrometeorological conditions may also be a factor in other hazards such as landslides, wildland fires, locust plagues, epidemics and in the transport and dispersal of toxic substances and volcanic eruption material.

Technological hazards originate from technological or industrial conditions, dangerous procedures, infrastructure failures or specific human activities. Examples include industrial pollution, nuclear radiation, toxic wastes, dam failures, transport accidents, factory explosions, fires and chemical spills. Technological hazards also may arise directly as a result of the impacts of a natural hazard event.

a disaster, there are several variations in use by different relevant organizations in the disaster literature, as outlined in Box 4:

The mortality definitions range from being very broad in their scope, as per the EM-DAT definition, to very specific, as per the Global Burden of Disease definition. Therefore, the varying adoption of these different definitions by those involved in enumerating disaster mortality has contributed to challenges in determining comparable estimates of the mortality impact across geographical locations and time. Disaster mortality can also be defined in multiple ways: deaths per the total population; deaths per population affected by the disaster; or deaths per the population exposed to the direct effects of the disaster. The choice of mortality definition can further contribute to comparability issues, as assessing who has been affected presents its own challenges (Guha-Sapir and Hoyois 2015) and has implications for the accuracy of reporting for the Sendai
Framework, and how far countries have come in reducing disaster mortality.

When considered in detail, defining a death that results from a disaster needs to consider both (1) the type of death and (2) the timescale over which the death is expected and can be attributed to a disaster in the context of different types of disasters.

\section{(1) Type of death}

Disasters are wide ranging in their type, impact, and likelihood of resulting in mortality. Analysis of the EM-DAT data found flooding to be the most common type of disaster, being associated with a large financial and health impact but a small number of fatalities. However, rare events can have a large impact and account for the highest proportion of mortality as demonstrated by the 2004 Asian Tsunami (UNISDR and CRED 2016, although tsunamis are classified under earthquakes in EM-DAT). Deaths 
Box 3: United Nations General Assembly endorsed Report of the Open-nded Intergovernmental Expert Working Group on Indicators and Terminology elated to Disaster Risk Reduction (A/71/644) agreed definition of a Disaster

"A serious disruption of the functioning of a community or a society at any scale due to hazardous events interacting with conditions of exposure, vulnerability and capacity, leading to one or more of the following: human, material, economic and environmental losses and impacts"

Annotations

The effect of the disaster can be immediate and localized, but is often widespread and could last for a long period of time. The effect may test or exceed the capacity of a community or society to cope using its own resources, and therefore may require assistance from external sources, which could include neighbouring jurisdictions, or those at the national or international levels.

Emergency is sometimes used interchangeably with the term disaster, as, for example, in the context of biological and technological hazards or health emergencies, which, however, can also relate to hazardous events that do not result in the serious disruption of the functioning of a community or society, therefore may require assistance from external sources, which could include neighbouring jurisdictions, or those at the national or international levels.

Disaster damage occurs during and immediately after the disaster. This is usually measured in physical units (e.g., square meters of housing, kilometres of roads, etc.), and describes the total or partial destruction of physical assets, the disruption of basic services and damages to sources of livelihood in the affected area.

Disaster impact is the total effect, including negative effects (e.g., economic losses) and positive effects (e.g., economic gains), of a hazardous event or a disaster. The term includes economic, human and environmental impacts, and may include death, injuries, disease and other negative effects on human physical, mental and social well-being.

For the purpose of the scope of the Sendai Framework for Disaster Risk Reduction 20152030 (para. 15), the following terms are also considered:

Small-scale disaster: a type of disaster only affecting local communities which require assistance beyond the affected community.

Large-scale disaster: a type of disaster affecting a society which requires national or international assistance.

Frequent and infrequent disasters: depend on the probability of occurrence and the return period of a given hazard and its impacts. The impact of frequent disasters could be cumulative, or become chronic for a community or a society.

A slow-onset disaster is defined as one that emerges gradually over time. Slow-onset disasters could be associated with, e.g., drought, desertification, sea-level rise, epidemic disease.

A sudden-onset disaster is one triggered by a hazardous event that emerges quickly or unexpectedly. Sudden-onset disasters could be associated with, e.g., earthquake, volcanic eruption, flash flood, chemical explosion, critical infrastructure failure, transport accident.

Box 4: Definitions of a disaster death

"The number of people who died during the disaster, or directly after, as a direct result of the hazardous event"

Sendai Framework (UNISDR 2017a)

"Killedpeople who lost their lives as a consequence of a hazardous event"

UNDRR OEIGWG preliminary reportnot included in final report as not agreed (UNISDR 2015c)

"Number of people who lost their life because the event happened"

EMDAT (CRED 2017)

"The number of deaths registered in a disaster loss database when the reporting by the original data source is stable and no longer changing"

IRDR (IRDR 2015)

"ICD-10 codes in vital registration data corresponding to exposure to forces of nature, disaster"

Global Burden of Disease (Haagsma et al. 2016)

resulting from disasters are generally disaggregated into direct deaths and indirect deaths as illustrated by the example in Table 1.

Reflection suggests a further category of "indirectly related" deaths, can be distinguished where a disaster may have exacerbated an individual's ill health, such as exhaustion, stress, and pre-existing chronic conditions.
(2) Timescale over which an event/disaster can cause deaths

Direct and indirect deaths can be further categorized into those that are short- or long-term depending on their temporal occurrence relative to an event's onset. For short-term disasters, most resulting deaths will occur rapidly, while in long-term disasters, deaths accumulate over time and require a longer response phase. 
Table 1 Examples of direct and indirect disaster death definitions. Source Adapted from IRDR (2015)

\begin{tabular}{|c|c|c|}
\hline Death & Description & Example \\
\hline Direct & Result directly from the disaster through physical force or other direct consequences & $\begin{array}{l}\text { Drowning from flooding } \\
\text { Heatstroke from heatwaves } \\
\text { Gunshots and blast wounds during conflict }\end{array}$ \\
\hline Indirect & $\begin{array}{l}\text { Result from the disaster but from other causes, when unsafe or unhealthy conditions } \\
\text { are present during any phase of a disaster and contribute to a death (Combs 1999) }\end{array}$ & $\begin{array}{l}\text { Electrocution and carbon monoxide poisoning } \\
\text { following storms } \\
\text { Acute malnutrition and outbreaks due to food } \\
\text { insecurity following droughts }\end{array}$ \\
\hline
\end{tabular}

Definitions that differ according to directness and temporality will therefore capture different types and numbers of deaths. To take the example of the Sendai Framework definition, while its use in monitoring progress will improve standardization and account for different national capacities for measuring mortality, its technical guidance (UNISDR 2017a) recommends focusing on short-term deaths that result as a direct effect of the hazardous event (as they are more feasible to attribute, collect, and report). Biological hazards include, according to the Sendai Framework, epidemics and pandemics and may impact a longer time scale such HIV/AIDS (Murray et al. 2017a). This is likely to result in an underestimation of certain types of disaster deaths, and disproportionately underestimate mortality from certain types of disasters that are prolonged, such as drought. Moreover, concentrating only on direct deaths compromises planning for emergency response and recovery. A health service's duty of care involves planning for short- to long-term direct and indirect health effects of disasters and continuing to provide expected lifesaving services should not be compromised by the emergence of another hazard.

\section{Sources of Data}

Mortality is estimated by calculating crude death rates, which requires two types of data: population data and death data.

\subsection{Population Data}

To improve comparability of estimates, population data are required to place the number of deaths in a country in context. The Sendai Framework guidance (UNISDR 2017a) recommends using the whole population of a country. This information is usually more readily obtainable through census data, although there are two limitations to be aware of with this approach. First, censuses are recommended to be conducted at least once every 10 years. As a result, when data are available, they are often out of date, particularly in countries with rapid population change. Inter-census estimates are available from organizations such as the World Bank, but these are often markedly revised when subsequent census estimates are available.

Second, if a disaster is localized, assessing the number of deaths in the context of the whole country's population will underestimate the impact of the disaster on affected populations. While this is of limited concern when looking at the absolute number of deaths, when comparing across time this may have implications for interpretation of trends within a given country. When determining rates, the population at risk is typically taken as the denominator and presented as person-time. This can be defined as the sum of the individual units of time where individuals were exposed to a hazard, which can often be very challenging to calculate.

\subsection{Death Data}

(1) Civil Registration and Vital Statistics Systems Irrespective of the cause of death, obtaining robust data on mortality is challenging. Countries with robust Civil Registration and Vital Statistics Systems (CRVS) typically monitor mortality through the continual registration of deaths, which are considered to produce the most thorough and accurate mortality statistics (Rampatige et al. 2014). There is a recognized need to improve these systems globally (Lo and Horton 2015), as approximately $60 \%$ of deaths go unaccounted for in registration systems globally (Mikkelsen et al. 2015; Clarke et al. 2017). More than 100 nations, primarily in low- and middle-income countries, lack functioning CRVS systems, with only $57 \%$ of countries, territories, and areas assessed by the UN Statistical Division having at least $90 \%$ death registration coverage in 2014 (Byass 2007; World Bank and WHO 2014). A CRVS scaling-up investment plan has set a goal of universal civil registration 
Fig. 2 Proportion of countries by region where vital registration data are available and proportional disaster impact. Source Vital registration data: United Nations Statistics Division (2017); proportional disaster impact: CRED (2017)

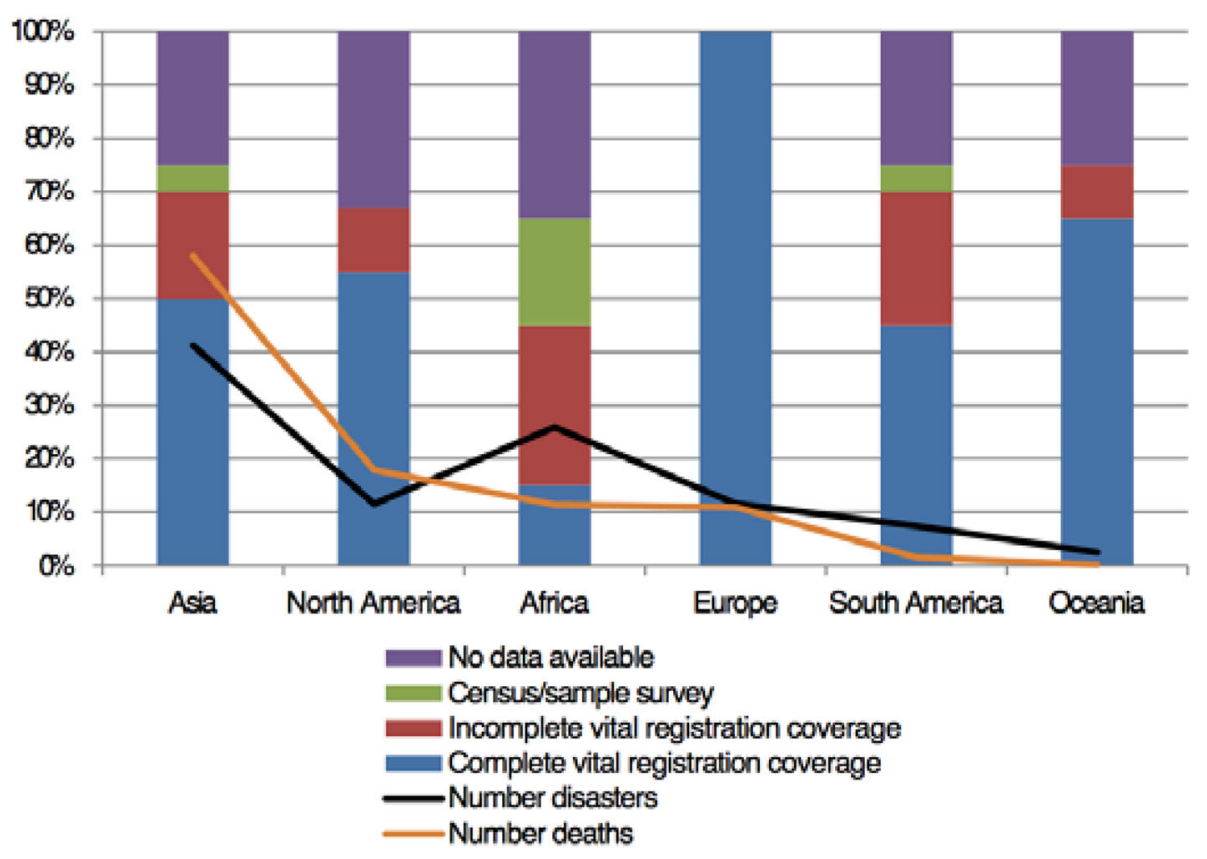

of deaths, including cause of death, for all individuals by 2030 (IEAG 2014).

Although all countries are vulnerable to disasters and loss of life, there is generally a higher exposure to disasters and the risk of death in low- and middleincome countries, which are the same countries that tend to lack vital registration data-further magnifying the data gap (Osuteye et al. 2017). This is summarized in Fig. 2.

(2) Disaggregated data

As well as accurate information on the scale of deaths, there is a need to determine which groups of the population are affected. While all communities are vulnerable to the risks associated with disasters, the risk of death is greatest among marginalized groups least likely to be identified in census data, such as those with disabilities and ethnic minorities. This also has implications for the robustness and ability to disaggregate that data (Ishiguro et al. 2015).

(3) Other approaches

Alternative approaches to CRVS systems for estimating mortality and its causes include household and hospital sample surveys and demographic surveillance sites (Hill 2007). However, as these are ad hoc and typically done through sampling, they are liable to introduce high levels of statistical inaccuracy into estimates if not reliable, valid, or replicable (SDSN TReNDS 2017). In addition, using hospital or healthcare facility records to estimate mortality assumes that affected populations have equal and continued access to health services and facilities during and after disasters.

\section{Disaster Mortality Estimation}

There are different ways to estimate disaster mortality and these estimates will vary according to the data sources available to calculate and if estimates are preliminary or refined over time.

\subsection{Counting Deaths in the Emergency Response Phase}

During the emergency response phase of a disaster, casualty numbers are typically approximated using body counts, household or hospital surveys, and inferences from assessments of infrastructural damage (Lapidos 2008). Depending on the institutional resources of the affected country, these approximations are made either by employees of governmental emergency response departments, or by multilateral organizations and nongovernmental organizations, with data subsequently relayed to governmental offices or the UN Office for the Coordination of Humanitarian Affairs (Lapidos 2008; Albala-Bertrand 2013). These initial rapid estimates are typically those most widely reported in the media.

By drawing on a range of sources, there will also be a range of reliability. As recommended by the Integrated Research on Disaster Risk program (IRDR 2015), when presenting data, information regarding their reliability should be included, such as a quality score or uncertainty level. This will facilitate interpretation and highlight any potential issues with the data. To improve reliability, when multiple surveys or samples are carried out and there is enough information to link individuals across such surveys, 
capture-recapture analysis can be undertaken to provide an overall estimate of disaster mortality. The only example found applied in the context of a disaster was carried out in Iraq to assess the extent to which first-hand reports of violent deaths associated with the 2003 invasion of Iraq were captured in the English language media, finding that $68-76 \%$ were not reported by the press, although this fell to $22 \%$ for deaths in more recent years with a lower impact of recall bias (Siegler 2008).

\subsection{Civil Registration and Vital Statistics Systems}

Following a disaster's emergency phase, mortality can be quantified through counting associated deaths in CRVS systems in countries where these systems are present. The primary cause of death is noted for most vital registration systems using the International Statistical Classification of Diseases and Related Health Problems 10th revision (ICD10) (WHO 2004). This classification uses unique alphanumeric codes to identify known diseases and other health problems and is used to compile cause-specific national mortality statistics.

In Saulnier et al. (2017), the authors undertook a systematic review of human health following flood and storm disasters. Their data from their review showed that the causes of deaths from, for example, flooding, are more than drowning and other causes are important to consider when documenting flood-related mortality, which are summarized below:

- Injuries and poisonings

- Drowning in flood waters

- Carbon monoxide poisoning

- Electrocution

- Crush injuries and asphyxia from structural collapse, landslides

- Infectious and parasitic diseases-Diarrhea, leptospirosis

- Noncommunicable diseases and chronic illnessesChronic pulmonary conditions

- Other

- Obstetric complications

Monitoring disaster mortality through vital registration systems alone has been shown to result in the potential underestimation of impacts (Choudhary et al. 2008). "Active mortality surveillance systems" can be established, which provide guidance to physicians and medical examiners on causes of death and mortality codes likely to arise because of a disaster. These have been shown to result in the identification of a significantly higher number of disaster deaths than gleaned from CRVS alone. For example, during Hurricane Ike in 2008, a review of vital statistics data found only four deaths in Texas to be hurricane related, but a rapidly implemented active mortality surveillance system identified 74 hurricane-related deaths (Choudhary et al. 2008).

Although efforts have been made by the United Nations to encourage more standardized death certification statements and coding practices, discrepancies persist in causeof-death classifications (Sibai 2004; Saulnier et al. 2017). Disaster deaths, particularly indirect, can be categorized under a variety of codes and formats and if disaster- and hazard-related terms are not recorded on death certificates, they are unlikely to be attributed to the disaster (Anderson 2011; Noe 2017). For example, the estimated number of deaths resulting from the Chernobyl disaster ranges widely, from 4000 up to 60,000 . The lower estimate does not include potential deaths from low-level exposure in populations further from the nuclear site, while the higher estimate includes direct fatalities at the nuclear facility, deaths in proximate areas resulting from high radiation exposure, and long-term deaths from low level radiation exposure (Our World in Data 2017). The US Centers for Disease Control and Prevention recently produced a toolkit and guidelines that may help improve the quality of the cause of death information included on death certificates, and therefore improve data on direct and indirect mortality from disasters after natural hazards (CDC 2017).

Similarly, direct and indirect deaths from Hurricane Katrina in 2005 are thought to be substantially underestimated, primarily because many storm-related deaths were not coded in a way that attributed them to the hazard (Brunkard et al. 2005; Ragan et al. 2008). The incidence of acute myocardial infarction at a hospital was reported to be elevated for up to 2 years post-hurricane when compared to pre-hurricane incidence (Gautam et al. 2009), additionally highlighting that indirect illnesses and deaths may occur over a long period of time and the difficulties in attributing them to the original disaster.

A suggested framework is outlined by the Sendai Framework guidance (UNISDR 2017a) for the classification of the types of death by disaster type for each member state and their recommended cut-off point. However, to ensure the focus is on consistent reporting within the country, the decision of exact causes of death and cut-offs has been left for each member state to decide on, impacting comparability between countries. It is recommended that common direct and indirect causes of death from different types of hazards and expected durations should be identified from the current evidence base and represented within the guidance to help enable reporting member states to more accurately identify and attribute mortality to disasters.

Furthermore, the period over which mortality is monitored needs to take into consideration delays in 
registrations of deaths. For example, deaths resulting from road traffic crashes in England can take up to 2 years to be registered (Devis and Rooney 1997). There will need to be a balance between collecting all known deaths and collecting the majority within a reasonable timeframe.

\subsection{Statistically Estimating Disaster Mortality}

Disaster mortality can be statistically estimated through excess mortality calculations. This involves modeling a baseline of expected levels of mortality and comparing what is observed to what is expected, the difference between which is termed "excess." This approach can provide an estimate, taking into account the limitations with counting of deaths and encompassing all types of disaster associated deaths. It can also provide estimates for countries where there are no death registration systems in place and/or cause of death information.

The definition of the baseline varies. For example, it can be estimated over a period of time preceding the disaster using average mortality rates for the time of year (the definition of which is crucial) and comparing patterns of mortality during the predefined period the rates during the event. Regression analysis can then be carried out, either through an interrupted time series approach or calculating relative risk of mortality post- compared to pre-disaster. The timescale of the impact of the hazard will dictate which timescale excess mortality should be measured on. For example, mortality in England follows a seasonal pattern with higher levels of mortality in the winter months compared to the summer months. The impact of cold weather is seen on a weekly scale (Office for National Statistics 2018b).

Predictive modeling is being used to estimate mortality and retrospectively "excess mortality" analysis is being carried out. For example, following Hurricane Maria in Puerto Rico, 16 deaths were estimated initially, with subsequent official revisions increasing this to 64 deaths (Robles 2017). However, Santos-Lozada and Howard (2017) calculate that the toll is likely over 1000 using an excess mortality methodology and a recent study that surveyed the community estimates the toll at 5740 excess deaths, nearly 70 times the official estimate (Kishore 2018). For estimated mortality, there will need to be a measure of uncertainty placed on the number and a range of estimates provided.

\subsection{Varying Estimates over Time}

There can be variation between different data sources and early and final estimates. While the Global Assessment Report on Disaster Risk Reduction in 2015 found differences in reported mortality were less than $15 \%$ among different data sources, this is probably an underestimate, and $15 \%$ can represent a significant number of missed deaths. There have been some examples where there has been a notable difference, for example during the UK 2013 heatwave where initial modeling predicted an estimated 650 people to have died prematurely during the heatwave based on observed temperatures, while later excess mortality calculations found the impact to be a fifth of that predicted at 195 deaths (Green et al. 2016).

Following a disaster, preliminary mortality estimates, which are best estimates but generally inaccurate (AlbalaBertrand 2013), are refined over time as more reliable data become available. During the 2009 influenza pandemic, in the first affected country of Mexico, a focus on surveillance of severe cases and uncertainty in the early stages on the total number of cases led to an initial estimated case fatality ratio of $5.6 \%$ (Lipsitch et al. 2009) compared to a revised estimate of $0.091 \%$ (Fraser et al. 2009). A further example is the 2010 Haiti Earthquake, the official mortality figure for which reported by the country was 316,000 , but which was later estimated at between 20 and $50 \%$ of this by the United States Agency for International Development a year after the disaster (New York Times 2011), with another study estimating 158,679 (Kolbe et al. 2010), although the estimates are still disputed. Another important factor to consider with disaster mortality estimates is therefore the need to update them when more reliable information becomes available.

\section{Discussion}

Following an outline of the challenges faced with estimating disaster mortality, recommendations are provided below for when considering the data and its interpretation.

\subsection{Suggested Recommendations for Interpreting the Challenges of Disaster Mortality Data}

As outlined in this article, there are numerous challenges around defining disaster mortality, utilizing appropriate data sources, collecting mortality data, estimating mortality, and reporting numbers. Awareness of these challenges and where possible, trying to address them, will help enable accurate and fair interpretation of the mortality estimates that will be received through the Sendai Framework. Recommendations can be made at the relevant levels, depending on who is involved at each stage, ranging from officials in countries responsible for submitting mortality data to the reporting capability of the Sendai Framework tool. Some such suggested recommendations are outlined below. 


\subsubsection{Definitions}

(1) Burden of hazardous events

Issue The focus on direct, short-term deaths will underestimate the burden of hazardous events generally, and specifically for hazards with long-term impacts such as drought.

Suggested recommendation For individuals interpreting the disaster mortality data, the type of hazardous event (including biological and technological hazards) and resulting types of deaths should be explicitly considered when determining and interpreting the data.

(2) Definition of the population when calculating mortality

Issue Typically, the population at risk is taken as the denominator when calculating rates. Using the whole population figure as the denominator is not representative of the population at risk if the disaster is localized to an area within the country and has the potential to underestimate the impact. This may also have implications for interpretation of trends over time within a given country and for different disasters.

Suggested recommendation The geographical coverage of a disaster within a country should be considered by individuals interpreting the scope of a disaster's impact on mortality.

\subsubsection{Estimates}

(1) Validity of estimates

Issue Different data sources will be used to generate estimates of disaster mortality with varying degrees of quality, which will affect the validity of the estimates.

Suggested recommendation For individuals collating and reporting data, incorporating a marker or score of quality for the type of data behind the figures could help place the findings in context.

(2) Range of estimates

Issue Statistical estimation of disaster mortality will come up with a range of mortality estimates, rather than a single estimate.

Suggested recommendation A range of estimates (if available) could be provided when reporting to the Sendai Framework. This has implications for the format and utility of the tool used by countries for reporting.

(3) Updating estimates

Issue Initial mortality estimates can vary markedly from the final validated (or unvalidated) estimates that, taking into account death registration delays and the type of disaster, may only become available up to a year later.

Suggested recommendation For reporting of mortality to the Sendai Framework, the ability to update estimates when more reliable data is available could be included.

\subsection{Interpretation of Progress in Disaster Risk Reduction}

The Sendai Framework indicators of disaster mortality estimates will be used to monitor progress in disaster risk reduction by assessing if Target $\mathrm{A}$ - to substantially reduce global disaster mortality by 2030 by aiming to lower average mortality in 2020-2030 compared to 2005-2015has been met. This in turn has challenges when considering the definition of baseline disaster mortality, when comparing across countries and disasters spanning multiple years.

(1) Baseline disaster mortality

Target A explicitly states disaster mortality in 2020-2030 should be compared to disaster mortality in 2005-2015. This therefore assumes consistency of reporting between the two time periods within the country. It also implies that mortality estimates are available for 2005-2015. For most countries this will not be the case and robust estimates will need to be produced, potentially through initiatives such as the Global Burden of Disease, which will then need to be applied to 2020-2030 to ensure consistent methodology. Data collectors also need to be clear on the definition of the 2005-2015 baseline-for example, if it is based on 2005 data, 2015 data, an average over the period of time, or the best available data for the entire time period (GBD 2015 Mortality and Causes of Death Collaborators 2016). Providing clarification could help enable consistent measurement against the target.

(2) Comparison across countries

The Sendai Framework indicator guidance permits country-level flexibility for the definition of cause of death and the timeframe of the hazard impact. This will therefore limit comparability between countries, with a focus on intra-country comparison. By providing a recommended range of causes of death and timeframe of impact, this could help to enable valid comparability between countries.

(3) Disasters spanning multiple years

Currently, deaths are recorded in the year they occurred in the Sendai Framework monitoring tool. This makes it challenging to interpret disaster impact, 
particularly if the disaster spans several years or occurs in the final days of a year. Therefore, the duration of a disaster should be considered when assessing figures.

\subsection{Data Access and Collection Considerations}

Users of data are rarely also the data owners. There can be significant delays in the publication of available data and, despite improvements in data integration, significant data silos remain, forming barriers to the use of the data. Therefore there needs to be clear processes in place for ensuring that data are accessible and available (IEAG 2014; European Commission 2015) to share with the Sendai Framework and target and indicator guidance, with robust data management plans in place. As well as ensuring sufficient data resources and capacity to achieve this, explicit consideration should be given to data governance, with transparent and politically independent National Statistical Offices. Ultimately, data should be FAIR-Findable, Accessible, Interoperable, and Reusable (European Commission 2016).

The collection and retention of data during disasters or humanitarian emergencies often occurs in high-pressure, time-critical situations (WHO 2015). Working in an emergency situation requires additional consideration of how data are collected and stored that may not need consideration in more routine or controlled circumstances (Mezinska et al. 2016). These can include the mental health and well-being of any interviewees after trauma, confirming their capacity to agree to participate, the storage of data if security is an issue, and cultural sensitivities of the area where data are being collected (SAMSA 2016). Furthermore, data protection and privacy issues need to be considered through the development of robust national policy and legal frameworks, supporting the protection, respect, and fulfilment of human rights (for example, whether personal information of the victims can be published).

Finally, there is currently a data revolution, with vastly increasing amounts of data and range of data sources relevant to disaster mortality. Within countries, consideration needs to be given to the practicalities of both storing the data and how best to integrate data in different formats.

\section{Conclusion}

Data-led approaches to disaster risk management help monitor progress in this field. While there are numerous highlighted challenges at all levels of the data collection and monitoring process to be addressed, their identification and collective consideration permit a more accurate interpretation of the data and improve the utility of the Sendai Framework.

Acknowledgements Jonathan Abrahams-World Health Organization Emergencies Programme, World Health Organization. Simon Hodson and Geoffrey Boulton-Committee on Data of the International Science Council (CODATA). Fernando Gouvea-Reis-Global Disaster Risk Reduction, Public Health England.

Open Access This article is distributed under the terms of the Creative Commons Attribution 4.0 International License (http://crea tivecommons.org/licenses/by/4.0/), which permits unrestricted use, distribution, and reproduction in any medium, provided you give appropriate credit to the original author(s) and the source, provide a link to the Creative Commons license, and indicate if changes were made.

\section{References}

Albala-Bertrand, J.M. 2013. Disasters and the networked economy. Routledge Studies in Development Economics. Oxon: Routledge.

Aitsi-Selmi, A., V. Murray, C. Wannous, C. Dickinson, D. Johnston, A. Kawasaki, A.S. Stevance, and T. Yeung. 2016. Reflections on a science and technology agenda for 21 st century disaster risk reduction. International Journal of Disaster Risk Science 7(1): $1-29$.

Anderson, R.N. 2011. Coding and classifying causes of death: Trends and international differences. In International handbook of adult mortality, ed. R. Rogers, and E. Crimmins, 467-489. Dordrecht: Springer.

Bouwer, L.M., and S.N. Jonkman. 2018. Global mortality from storm surges is decreasing. Environmental Research Letters 13(1): Article 014008.

Brunkard, J., N. Gonza, and R. Raoult. 2005. Hurricane Katrina deaths, Louisiana, 2005. Disaster Medicine \& Public Health Preparedness 20(4): 215-223.

Byass, P. 2007. Who needs cause-of-death data? PLOS Medicine 4(11): 1715-1716.

CDC (Centers for Disease Control and Prevention). 2017. Death scene investigation after natural disaster or other weatherrelated events toolkit, 1st edn. Atlanta, GA: CDC.

Choudhary, E., F.Z. David, C. Beasley, R. Jones, A. Rey, R.S. Noe, C. Martin, A.F. Wolkin, and T.M. Bayleyegn. 2008. Evaluation of active mortality surveillance system data for monitoring hurricane-related deaths-Texas, 2008. Prehospital Disaster Medicine 27(4): 392-397.

Clarke, L., K. Blanchard, R. Maini, A. Radu, Z. Zaidi, and V. Murray. 2017. Knowing what we know-reflections on the development of technical guidance for loss data for the Sendai Framework for Disaster Risk Reduction. PLOS Currents Disasters 1. https://doi. org/10.1371/currents.dis.537bd80d1037a2ffde67d66c604d2a78.

Combs, D.L., L.E. Quenemoen, P.R. Gibson, and J.H. Davis. 1999. Assessing disaster-attributed mortality: Development and application of a definition and classification matrix. International Journal of Epidemiology 28(6): 1124-1129.

CRED (Centre for Research on the Epidemiology of Disasters). 2017. EM-DAT: The international disaster database explanatory notes. Brussels: CRED. http://www.emdat.be/explanatory-notes. Accessed 19 Mar 2017.

de Souza Boeno, R.K., and V. Soromenho-Marques. 2017. Climate deterrence: Disasters and security after COP 21. In Information technology in disaster risk reduction: First IFIP TC 5 DCITDRR 
International Conference, ed. Y. Murayama, D. Velev, P. Zlateva, and J. Gonzalez, 119-138. Switzerland: Springer International Publishing.

DesInventar. 2018. Inventory system of the effects of disasters. Cali, Colombia: Desinventar. https://www.desinventar.org/en/desin ventar.html. Accessed 15 Aug 2018.

Devis, T., and C. Rooney. 1997. The time taken to register a death (registration of death in the United Kingdom). Population Trends 88: 48-55.

European Commission. 2015. JRC science and policy reportsGuidance for recording and sharing disaster damage and loss data. Ispra, Italy: EC.

European Commission. 2016. Horizon 2020 Commission expert group on turning FAIR data into reality (E03464). http://ec. europa.eu/transparency/regexpert/index.cfm?do=groupDetail. groupDetail\&groupID=3464. Accessed 15 Aug 2018.

European Commission. 2018. Human impact by disasters in 2017. Brussels: ECHO. http://erccportal.jrc.ec.europa.eu/emaildaily map/title/ECHO\%20Daily\%20Map\%20of\%2016\%20April\% 202018. Accessed 16 Aug 2018.

Fraser, C., C.A. Donnelly, S. Cauchemez, W.P. Hanage, M.D. Van Kerkhove, T.D. Hollingsworth, J. Griffin, R.F. Baggaley, et al. 2009. Pandemic potential of a strain of influenza A (H1N1): Early findings. Science 324(5934): 1557-1561.

Gautam, S., J. Menachem, S.K. Srivastav, P. Delafontaine, and A. Irimpen. 2009. Effect of Hurricane Katrina on the incidence of acute coronary syndrome at a primary angioplasty center in New Orleans. Disaster Medicine and Public Health Preparedness 3(3): 144-150.

GBD 2015 Mortality and Causes of Death Collaborators. 2016. Global, regional, and national life expectancy, all-cause mortality, and cause-specific mortality for 249 causes of death, 1980-2015: A systematic analysis for the Global Burden of Disease Study 2015. The Lancet 388(10053): 1459-1544.

Green, H.K., N.J. Andrews, B. Armstrong, G. Bickler, and R.G. Pebody. 2016. Mortality during the 2013 heatwave in EnglandHow did it compare to previous heatwaves? A retrospective observational study. Environmental Research 147: 343-349.

Guha-Sapir, D., and P. Hoyois. 2015. Estimating populations affected by disasters: A review of methodological issues and research gaps. Brussels: CRED and IRSS.

Haagsma, J.A., N. Graetz, I. Bolliger, M. Naghavi, H. Higashi, E.C. Mullany, S.F. Abera, J.P. Abraham, et al. 2016. The global burden of injury: Incidence, mortality, disability-adjusted life year estimates and time trends from the Global Burden of Disease Study 2013. Injury Prevention 22(1): 3-18.

Hill, K., A.D. Lopez, K. Shibuya, and P. Jha. 2007. Interim measures for meeting needs for health sector data: Births, deaths and causes of death. The Lancet 370(9600): 1726-1735.

IEAG (Independent Expert Advisory Group on a Data Revolution for Sustainable Development). 2014. A world that counts-Mobilising the data revolution for sustainable development. Report prepared at the request of the United Nations Secretary-General, by the IEAG. http://www.undatarevolution.org/wp-content/ uploads/2014/12/A-World-That-Counts2.pdf. Accessed 15 Aug 2018.

International Digital Health Conference. 2018. Public health and emergencies in the age of big data. https://www.acm-digital health.org/2018/highlights-from-2018-2/index.html. Accessed 18 Sept 2019.

IRDR (Integrated Research on Disaster Risk). 2015. Guidelines on measuring losses from disasters: Human and economic impact indicators (IRDR Data Publication No. 2). Beijing: Integrated Research on Disaster Risk.

Ishiguro, A., Y. Togita, M. Inoue, T. Ohkubo, and E. Yano. 2015. Identification of disaster-vulnerable communities by use of census data prior to the Great East Japan Earthquake. Disaster Medicine and Public Health Preparedness 9(1): 19-28.

Kishore, N., D. Marqués, A. Mahmud, M.V. Kiang, I. Rodriguez, A. Fuller, P. Ebner, C. Sorensen, et al. 2018. Mortality in Puerto Rico after Hurricane Maria. New England Journal of Medicine 379(2): 162-170.

Kolbe, A.R., R.A. Hutson, H. Shannon, E. Trzcinski, B. Miles, N. Levitz, M. Puccio, L. James, et al. 2010. Mortality, crime and access to basic needs before and after the Haiti Earthquake: A random survey of Port-au-Prince households. Medicine Conflict and Survival 26(4): 281-297.

Lapidos, J. 2008. Natural-disaster death tolls: Who's counting? Slate. http://www.slate.com/articles/news_and_politics/explainer/ 2008/05/naturaldisaster_death_tolls.html. Accessed 15 Aug 2018.

Lipsitch, M., F.G. Hayden, B.J. Cowling, and G.M. Leung. 2009. How to maintain surveillance for novel influenza A H1N1 when there are too many cases to count. The Lancet 374(9696): 1209-1211.

Lo, S., and R. Horton. 2015. Everyone counts-So count everyone. The Lancet 386(10001): 1313-1314.

Mezinska, S., P. Kakuk, G. Mijaljica, M. Waligóra, and D.P. O’Mathúna. 2016. Research in disaster settings: A systematic qualitative review of ethical guidelines. BMC Medical Ethics 17(1): Article 62.

Mikkelsen, L., D.E. Phillips, C. AbouZahr, P.W. Setel, D. de Savigny, R. Lozano, and A.D. Lopez. 2015. A global assessment of civil registration and vital statistics systems: Monitoring data quality and progress. The Lancet 386(10001): 1395-1406.

Murray, V., M. Catchpole, M. Hagenlocher, R. Maini, C. Margarita Montesinos Guevara, C. Roth, C. Sellwood, and T. Yeung. 2017a. Biological risk: Epidemics. In Science for disaster risk management 2017: Knowing better and losing less, ed. K. Poljanšek, M. Marín Ferrer, T. De Groeve, and I. Clark, 306-315. Luxembourg: Publications Office of the European Union.

Murray, V., R. Maini, L. Clarke, and N. Eltinay. 2017b. Policy brief: Coherence between the Sendai Framework, the SDGs, the Climate Agreement, New Urban Agenda and the World Humanitarian Summit, and the role of science in their implementation. Paris: International Council for Science.

Noe, R.S. 2017. Applications: Disaster-related mortality surveillance: Challenges and considerations for local and state health departments. In Disaster epidemiology: Methods and applications, ed. J.A. Horney, 55-63. Cambridge, USA: Academic Press.

OECD (Organization for Economic Cooperation and Development). 2018. Assessing the real cost of disasters: The need for better evidence, OECD reviews of risk management policies. Paris: OECD Publishing.

Office for National Statistics. 2018a. UK data gaps: Inclusive data action plan towards the global sustainable development goal indicators. London: UK Office for National Statistics.

Office for National Statistics. 2018b. Excess winter mortality in England and Wales: 2017 to 2018 (provisional) and 2016 to 2017 (final). London: UK Office for National Statistics.

Osuteye, E., C. Johnson, and D. Brown. 2017. The data gap: An analysis of data availability on disaster losses in Sub-Saharan African cities. International Journal of Disaster Risk Reduction 26: 24-33.

Our World in Data. 2017. What was the death toll from Chernobyl and Fukushima? https://ourworldindata.org/what-was-the-deathtoll-from-chernobyl-and-fukushima. Accessed 15 Aug 2018.

Ragan, P., J. Schulte, S.J. Nelson, and K.T. Jones. 2008. Mortality surveillance: 2004 to 2005 Florida hurricane-related deaths. American Journal of Forensic Medical Pathology 29(2): $148-153$ 
Rampatige, R., L. Mikkelsen, B. Hernandez, I. Riley, and A.D. Lopez. 2014. Hospital cause-of-death statistics: What should we make of them? Bulletin of the World Health Organization 92(1): 3-3A.

Robles, F., D. Kenan, S. Fink, and S. Almukhtar. 2017. Official toll in Puerto Rico: 64 actual deaths may be 1,052. The New York Times. https://www.nytimes.com/interactive/2017/12/08/us/ puerto-rico-hurricane-maria-death-toll.html. Accessed 15 Feb 2019.

SAMSA (Substance Abuse and Mental Health Services Administration). 2016. Disaster technical assistance center supplemental research bulletin: Challenges and considerations in disaster research. https://www.samhsa.gov/sites/default/files/dtac/supple mental-research-bulletin-jan-2016.pdf. Accessed 18 Sept 2019.

Santos-Lozada, A.R., and J.T. Howard. 2017. Estimates of excess deaths in Puerto Rico following Hurricane María. SocArXiv. https://osf.io/preprints/socarxiv/s7dmu/. Accessed 18 Sept 2019.

Saulnier, D.D., K. Brolin Ribacke, and J. von Schreeb. 2017. No calm after the storm: A systematic review of human health following flood and storm disasters. Prehospital and Disaster Medicine 32(5): 1-12.

SDSN TReNDS. 2017. Counting on the world: Building modern data systems for sustainable development. Paris: Sustainable Development Solutions Network.

Sibai, A.M. 2004. Mortality certification and cause-of-death reporting in developing countries. Bulletin of the World Health Organization 82(2): 83-83A.

Siegler, A., L. Roberts, E. Balch, E. Bargues, A. Bhalla, C. Bills, E. Dzeng, Y. Epelboym, et al. 2008. Media coverage of violent deaths in Iraq: An opportunistic capture-recapture assessment. Prehospital and Disaster Medicine 23(4): 369-371.

UNISDR (United Nations International Strategy for Disaster Reduction). 2015a. Sendai framework for disaster risk reduction 20152030. Geneva: UNISDR.
UNISDR (United Nations International Strategy for Disaster Reduction). 2015b. Launch of the 2015 global assessment report on disaster risk reduction. New York: UNISDR.

UNISDR (United Nations International Strategy for Disaster Reduction). 2015c. Annex to the working background text on indicators for the 7 global targets of the Sendai Framework for Disaster Risk Reduction. Geneva: UNISDR.

UNISDR (United Nations International Strategy for Disaster Reduction). 2017a. Technical guidance for monitoring and reporting on progress in achieving the global targets of the Sendai Framework for Disaster Risk Reduction: Collection of technical notes on data and methodology. Geneva: UNISDR.

UNISDR (United Nations International Strategy for Disaster Reduction). 2017b. Terminology on disaster risk reduction. Geneva: UNISDR.

UNISDR and CRED (United Nations International Strategy for Disaster Reduction and Centre for Research on the Epidemiology of Disasters). 2016. Poverty \& death: Disaster mortality 1996-2015. Geneva and Brussels: UNISDR and CRED.

United Nations Statistics Division. 2017. Coverage of birth and death registration. https://unstats.un.org/unsd/demographic-social/crvs/. Accessed 18 Sept 2019.

WHO (World Health Organization). 2004. ICD-10: International statistical classification of diseases and related health problems: Tenth revision, 2nd edn. World Health Organization. https:// apps.who.int/iris/handle/10665/42980. Accessed 18 Sept 2019.

WHO (World Health Organization). 2015. Ethics in epidemics, emergencies and disasters: Research, surveillance and patient care: Training manual. Geneva: WHO.

World Bank and WHO (World Health Organization). 2014. Global civil registration and vital statistics: Scaling up investment plan 2015-24. Washington, DC: World Bank Group. 